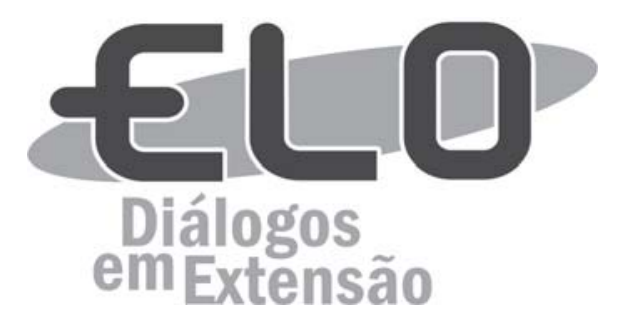

\title{
Oficina de corpo e dança: uma experiência interdisciplinar no âmbito das políticas públicas de enfrentamento à violência contra as mulheres
}

Emmanuela Neves Gonsalves ${ }^{1}$; Amanda Duarte Moura ${ }^{2}$; Tayane Torres dos Santos ; Janine Messina ; Erika Fernanda Marins de Carvalho ${ }^{5}$

\begin{abstract}
Resumo: O trabalho apresenta uma reflexão sobre a oficina de corpo e dança com mulheres, empreendida em um serviço de atendimento às mulheres em situação de violência no município do Rio de Janeiro. A oficina de corpo e dança se refere a um trabalho dialógico desenvolvido por uma equipe interdisciplinar composta por uma profissional de psicologia e alunas do curso de Dança. Para o presente artigo, foram analisados os sessenta e cinco relatos produzidos pelas estagiárias de dança e pela psicóloga ao longo do trabalho de um ano de oficina. A partir do estudo dos relatos foi possível construir quatro categorias de análise: a estrutura das oficinas, a questão da interdisciplinaridade, os corpos nas oficinas e as falas nas oficinas. As reflexões propostas apontam para a importância de ações interdisciplinares no campo das políticas públicas de enfrentamento à violência contra as mulheres.
\end{abstract}

Palavras-chave: Oficina de dança. Violência de gênero. Políticas públicas.

Área Temática: Gênero; Políticas Públicas; Direitos Humanos; Teorias e Metodologias em Extensão.

\section{Body and dance workshop: an interdisciplinary experience in the field of public policies for coping with violence against women}

\begin{abstract}
The work shows a reflection on the body and dance workshop for women, developed in a care service for women in violence condition in the city of Rio de Janeiro. The body and dance workshop refers to a dialogical study lead by an interdisciplinary team consisted of a psychology professional and dance class students. For the current article, there have been the analyses of sixty five reports made, during a year of workshop, by the dance trainees and the psychologist. From analysing the reports, four categories were created: the structure, the interdisciplinary issue, the bodies and the speeches in the workshops. The proposed reflection points to the importance of interdisciplinary actions in the field of public policies for coping with violence against women.
\end{abstract}

Keywords: Dance workshop. Gender violence. Public policies.

\footnotetext{
${ }^{1}$ Universidade Federal do Rio de Janeiro (UFRJ). Endereço: Rua São Fracisco Xavier, 246/apt. 701. Tijuca - Rio de Janeiro - RJ. CEP: 20550-012. Telefone: (21)988467823. E-mail: emmanuelaneves@yahoo.com.br.

${ }^{2}$ Universidade Federal Fluminense (UFF). Endereço: Estrada Velha da Estrela, km 68- Meio da Serra- Petrópolis/RJ. Telefone: 21-992773616. E-mail: amandadu.psico@gmail.com.

${ }^{3}$ Universidade Federal do Rio de Janeiro (UFRJ). Endereço: Rua Velinda Maurício da Fonseca, 106/202 - Cachambi - Rio de Janeiro - RJ. Telefone: (21) 972325411. Email: tayane_torres@yahoo.com.br.

${ }^{4}$ Universidade Federal do Rio de Janeiro (UFRJ). Endereço: Rua São Francisco Xavier, 246/apt. 701. Tijuca - Rio de Janeiro - RJ. CEP: 20550-012. Telefone: (21)976417709. E-mail: nini_messina@hotmail.com.

${ }^{5}$ Universidade Federal do Rio de Janeiro (UFRJ). Coordenadora do Centro de Referência de Mulheres da Maré Carminha Rosa (CRMM-CR), co-autora do artigo. Endereço: Rua Anverino Floresta De Miranda, 65. Freguesia. Jacarepaguá, Rio de Janeiro - RJ. CEP: 22743-510. . Telefone: (21)996634529. E-mail: erika.crmm@gmail.com.
} 


\section{Oficina de cuerpo y danza: una experiencia interdisciplinaria en el ámbito de las politicas públicas de enfrentamiento a la violencia contra las mujeres}

Resumen: El trabajo presenta una reflexión sobre el taller de cuerpo y danza con mujeres, emprendida en un servicio de atención a las mujeres en situación de violencia en el municipio de Río de Janeiro. El taller de cuerpo y danza se refiere a un trabajo dialógico desarrollado por un equipo interdisciplinario compuesta por una profesional de psicología y alumnas del curso de Danza. Para el presente artículo, se analizaron los sesenta y cinco relatos producidos por las pasantes de danza y por la psicóloga a lo largo del trabajo de un año de taller. A partir del estudio de los relatos fue posible construir cuatro categorías de análisis: la estructura de los talleres, la cuestión de la interdisciplinariedad, los cuerpos en los talleres y las palabras en los talleres. Las reflexiones propuestas apuntan la importancia de acciones interdisciplinares en el campo de las politicas públicas de enfrentamiento a la violencia contra las mujeres.

Palabras clave: Taller de danza. Violencia de género. Políticas públicas.

\section{Introdução}

O presente artigo objetiva apresentar uma proposta metodológica de trabalho, no âmbito das políticas públicas de enfrentamento à violência contra as mulheres, a partir da exposição e reflexão sobre uma experiência interdisciplinar em uma oficina sociocultural de corpo e dança realizada junto a mulheres no Centro de Referência de Mulheres da Maré Carminha Rosa (CRMM-CR).

Parte integrante da Política Nacional de Enfrentamento à Violência contra as Mulheres e um programa de extensão da Universidade Federal do Rio de Janeiro (UFRJ), o Centro de Referência de Mulheres da Maré oferece serviços de atendimento às mulheres, com o foco na questão da violência de gênero. São desenvolvidas atividades individuais e em grupo junto às mulheres, ações voltadas para a articulação da rede local e da rede especializada no atendimento às mulheres em situação de violência e, ainda, prima-se pela formação de quadros técnicos capacitados para o trabalho junto à questão da violência de gênero.

A presente produção acadêmica abordará o projeto Oficinas Socioculturais, um dos projetos de atendimento às mulheres desenvolvido pelo CRMM-CR que tem por objetivo "[...] fortalecer a cidadania feminina, a garantia de direitos e a prevenção da violência de gênero." (Higor SOUZA, 2014, sem página), a partir do protagonismo de estudantes de graduação da UFRJ, provenientes de diferentes campos de saber. No escopo deste projeto, será apresentada a experiência da oficina sociocultural de corpo e dança, ministrada por duas estudantes do curso de graduação em dança da UFRJ e acompanhada por uma psicóloga.

A partir da análise dos relatos produzidos pelas estagiárias e psicóloga que participaram da oficina foi possível a exposição de quatro categorias de análise: a estrutura das oficinas, a questão da interdisciplinaridade, os corpos nas oficinas e as falas nas oficinas.

Consideramos o presente trabalho relevante, tendo em vista que de acordo com Roberto Cruz (2016), as publicações dos processos de intervenção dos profissionais em seus determinados campos é essencial para o "[...] processo de construção e aperfeiçoamento do conhecimento científico sobre a realidade, tornando as informações produzidas acessíveis e úteis à comunidade." (p. 3).

Dessa forma, pretende-se contribuir para a reflexão sobre os trabalhos de corpo junto às mulheres, a ampliação do conhecimento sobre o trabalho interdisciplinar realizado nos serviços de atenção às mulheres em situação de violência e para a reflexão sobre as múltiplas possibilidades de formação e capacitação profissional no âmbito da extensão universitária.

\section{Metodologia}

Com o objetivo de conhecer diferentes estudos sobre o trabalho de oficinas de dança junto a mulheres, foi realizada uma busca por produções acadêmicas na plataforma SciELO (Scientific Electronic Library Online $)^{6}$. Com as palavras-chave utilizadas 'dança, oficina e mulher', nenhum artigo foi encontrado. Em uma busca no banco de teses da Universidade de São Paulo (USP), encontramos uma dissertação de mestrado que trata da análise de diversos recursos culturais e 
artísticos, dentre eles, atividades de dança do ventre desenvolvidos em um serviço de acolhimento às mulheres, com o objetivo de fomentar o empoderamento feminino, bem como reduzir as vulnerabilidades de gênero (GINA ARDILA OSORIO, 2015). Considerando que apenas um artigo foi encontrado nesta busca, é importante ressaltar a escassez de estudos sobre a temática proposta.

Para a apresentação da experiência em questão, foram analisados todos os relatos produzidos a partir da realização das oficinas, ao longo de um ano. Estes foram elaborados pelas alunas de dança da UFRJ, que ministraram as oficinas, e pela psicóloga que acompanhou os encontros.

Ao todo foram realizados cinquenta aulas e produzidos sessenta e cinco relatos sobre as atividades desenvolvidas. Por meio de um estudo minucioso destes relatos, foi possível construir reflexões relacionadas a quatro categorias de análise: a estrutura da oficina, a questão da interdisciplinaridade, os corpos nas oficinas e as falas nas oficinas.

\section{Estrutura da oficina}

Como um programa de extensão, o Centro de Referência de Mulheres da Maré constitui em um espaço privilegiado de formação profissional. De acordo com Cruz (2016), "formar profissionalmente pessoas para atuar em um país é uma tarefa complexa e de responsabilidade social acentuada." (p. 4). Tendo em vista esta questão, os profissionais do Centro de Referência têm reunido esforços para que o estágio no serviço seja o momento de interação entre o ensino e as demandas da população: “A responsabilidade civil e profissional acentua-se à medida que aumenta a interação entre o processo de formação e as exigências de atendimento de demandas da população e das instituições sociais." (CRUZ, 2016, p. 4).

As oficinas socioculturais de corpo e dança de que trataremos neste artigo foram realizadas ao longo de um ano e divididas em duas turmas. Cada turma era ministrada por uma das oficineiras de dança, estudantes do curso de bacharel em dança da UFRJ e, ambas as turmas, eram acompanhadas pela psicóloga do serviço. Os encontros de cada turma eram semanais, com a duração de duas horas cada e, todo o conteúdo das aulas, era planejado a partir do plano de curso e planos de aula, construídos pelas estagiárias do projeto, a psicóloga e as professoras do curso de Dança da Universidade que atuavam na supervisão das alunas.

A proposta da oficina foi sintetizada da seguinte forma:

A oficina de Dança propõe, através da relação ontológica com o corpo e a descoberta dos movimentos deste, a construção da cidadania feminina. Também, numa perspectiva dialógica, seus objetivos estão ligados ao empoderamento das mulheres por meio da conscientização do corpo e da construção de novas relações com o espaço e com o outro, à promoção dos escapes dos automatismos da vida cotidiana a partir do prazer de dançar e à criação de um ambiente favorável à construção de redes de solidariedade entre as mulheres. (SOUZA, GONSALVES e CONSOLE, 2013, p. 5).

O conteúdo da oficina foi dividido em cinco unidades e baseado na Teoria "Fundamentos da Dança de Helenita de Sá Earp"7, que consiste no estudo das possibilidades corporais e na descoberta de suas potencialidades, por meio de trabalhos focados no corpo, no movimento, no espaço, na forma, na dinâmica e no tempo.

As unidades foram organizadas a fim de promover um espaço de integração junto às participantes, assim como potencializar o conhecimento do corpo como um todo e de suas partes, além de promover a descoberta de alguns movimentos e propiciar novas formas de execução de outros já experienciados. Contamos, ainda, com uma unidade em aberto para que pudéssemos construir as atividades de acordo com o andamento e necessidade do grupo. Dessa forma foi possível desenvolver o trabalho anual a partir de cinco unidades: a apresentação, o corpo e suas partes, o espaço e a forma, o ritmo e a dinâmica e a finalização.

A estrutura dos encontros era organizada em "momentos". O "momento de chegada" onde as mulheres se voltavam para si, atrelado a um "momento de relaxamento"; um "momento de aquecimento das partes do corpo", seguido por um "momento de sequência de movimentos previamente definidos" e um "momento de laboratório de criação em dança". Os laboratórios e as respostas das mulheres a 
eles nunca se repetiam. Desses laboratórios surgiam movimentos criados pelas mulheres, coreografias construídas pelo grupo, etc. Alguns materiais que surgiam eram mais marcantes e o grupo manifestava o desejo de apresentá-los. Esses trabalhos não foram desenvolvidos com a finalidade de apresentar para o público externo, mas pelo prazer desinteressado de criar e construir movimentos e ideias que externassem seus pensamentos e sentimentos a partir da expressão corporal, transformando-os, assim, em dança. Na prática, os "momentos" não seguiam necessariamente esta ordem e nem sempre todos aconteciam.

Como a proposta se referia à possibilidade de uma construção coletiva, a flexibilidade, a mudança de planos e o improviso estavam previstos neste planejamento e geriam o cotidiano.

Cabe ressaltar que ao longo deste texto não será feita distinção em relação às duas turmas, as oficinas socioculturais de corpo e dança serão referenciadas como um todo, pois, foi dessa forma que ela foi experienciada por todas as atrizes envolvidas no processo, inclusive, algumas alunas, participavam de ambas as oficinas.

Em relação ao público, participaram vinte e duas mulheres ao longo do ano, em geral, mulheres não naturais do Rio de Janeiro, com mais de 40 anos. Foi observada grande rotatividade nas oficinas e, ao final do ano, apenas seis mulheres tinham presença constante nos últimos encontros.

A oficina funciona como porta de entrada para outras atividades oferecidas pelo Centro.-Em alguns casos, foi possível estabelecer uma relação entre o trabalho grupal a partir da oficina e o trabalho individual a partir do atendimento interdisciplinar. As questões que eram trazidas pelas mulheres eram trabalhadas nas oficinas ao longo das aulas e, quando possível, ocorriam os encaminhamentos para os atendimentos individuais, como apontam os relatos:

M. comentou que estava precisando conversar com uma psicóloga, pois ultimamente não estava muito bem, estava se questionando muito por não ter se deixado passar por determinadas experiências na sua vida. (Relato 2208 E1).

Em outro relato,

[...] Conversei com ela e indiquei que marcasse um atendimento com um advogado do centro para lhe ajudar a esclarecer suas dúvidas e auxiliá-la para onde seguir e resolver esse problema. (Relato $2208 \mathrm{E} 1$ ).

Sendo assim, é possível considerar o projeto das oficinas socioculturais como parte integrante do projeto mais amplo de atendimento às mulheres em situação de violência. Nesse sentido, em alguns momentos, as mulheres compreendiam aquele espaço da oficina como um espaço privilegiado para o atendimento, preterindo, assim, do atendimento individual interdisciplinar:

E. disse que foi chamada para ser atendida no acolhimento, mas disse que não precisava, pois já podia conversar comigo e com A. na oficina. (Relato 1609 E2).

Como um dos objetivos das oficinas socioculturais se refere à promoção do exercício da cidadania feminina, uma das atividades se refere a encontros das mulheres em espaços de cultura e de artes. Como aponta Souza (2014), as oficinas devem ser desenvolvidas com a utilização de metodologias como as atividades culturais. Essas eram escolhidas juntamente às mulheres e a apropriação do espaço da cidade constituía um dos focos dessas atividades. Algumas aulas também foram realizadas em espaços externos, como no Parque Lage e na Quinta da Boa Vista ${ }^{8}$. Essas atividades externas eram, em geral, vivenciadas muito intensamente pelas mulheres, tendo em vista alguns entraves que dificultavam a saída delas da comunidade, como conflitos armados frequentes, os altos preços das passagens dos ônibus, único transporte público possível de ser utilizado naquela região, as dificuldades de transportar as crianças ou de ter com quem deixá-las, a falta de informação e a dificuldade de locomoção em razão da idade. 


\title{
Interdisciplinaridade
}

A perspectiva do trabalho interdisciplinar se configura como um aspecto desafiador para a dinâmica do trabalho em equipe, onde se agrega distintos saberes, em campos diversos. Para além da ideia de multidisciplinaridade, que faz referência à composição de diversos profissionais numa mesma equipe, segundo Ana Teresa Ramos-Cerqueira (1994) "[...] a interdisciplinaridade deve caracterizar a colaboração existente entre disciplinas diversas ou entre setores heterogêneos de uma mesma ciência." (p. 37). Ou seja, a característica mais marcante do trabalho interdisciplinar é a integração, o diálogo e a troca entre profissionais e/ou campos científicos.

Ainda que se configure como um desafio, dada a leitura fragmentada que algumas áreas de saber têm em relação ao indivíduo, tal prática se mostra como de significativa importância, pois como afirmam Leandra Couto et al (2013), a interdisciplinaridade deve ser vista "[...] como uma possibilidade de contribuição para maior resolutividade dos problemas enfrentados, assim como para identificação de um objeto comum a vários profissionais." (p. 503).

Ocimar Dacome (2000), ao problematizar o conceito de trabalho interdisciplinar e relacionálo às dinâmicas num contexto institucional, afirma que tal prática permite problematizar tanto o papel institucional quanto o olhar que pretendemos direcionar ao indivíduo, objeto de nossa atuação:

\begin{abstract}
O trabalho interdisciplinar, mais que uma atuação, coloca em confronto os valores sociais, pois questiona o saber institucionalizado, entendido como acabado, e que compromete a possibilidade de se ter uma perspectiva mais totalizadora do indivíduo. [...] A proposta de um trabalho interdisciplinar não consiste em reunir tecnólogos, mas em promover a atuação participativa, reflexiva, contribuindo para a formação de seus atores pensantes, questionadores, e não apenas reprodutores do sistema." (DACOME, 2000, p. 93).
\end{abstract}

Nesse sentido, o CRMM-CR, por se configurar como um programa de extensão, torna-se locus de atuação prática para cursos de graduação da UFRJ e a partir de 2013, com a implantação do curso de Residência Multiprofissional em Política de Gênero e Direitos Humanos do Núcleo de Estudos em Políticas Públicas e Direitos Humanos, torna-se campo dos módulos práticos para os residentes que atuavam de forma interdisciplinar. Assim, todas as atividades desenvolvidas pelos técnicos, residentes e estagiários que compunham o quadro técnico do serviço se referiam a ações interdisciplinares.

Considerando a proposta de desenvolvimento de intervenções interdisciplinares, a psicologia entra neste cenário das oficinas socioculturais e, mais especificamente, a oficina de corpo e dança no ano em 2014, a partir da disponibilidade da profissional técnica da área em acompanhar as atividades neste espaço. A indecisão em relação à forma de acompanhar a oficina se fez presente em alguns momentos ao longo dos encontros realizados e, tal acompanhamento se deu, por vezes, como lugar de conflito devido aos questionamentos sobre a atuação da psicologia naquela atividade. A apreensão sobre o modo de realizar determinadas intervenções no espaço das oficinas se fazia constante, mas, ainda assim, permitia uma reflexão sobre como a referida área de conhecimento poderia contribuir num espaço onde o corpo era a principal via de intervenção. Esse momento de apreensão, longe de dificultar o trabalho, permitiu a profissional se aproximar das leituras referentes à dança, corpo e às práticas interdisciplinares, fazendo com que o trabalho acontecesse de modo mais fluido.

Atentar para a forma de atuar nesse outro lugar - que não o habitual espaço da fala individual - foi uma das inquietações surgidas nos momentos iniciais das atividades naquele espaço. A dúvida em "saber fazer a intervenção no momento adequado" ou em "como será que as mulheres percebiam uma profissional da psicologia naquele espaço" atravessavam o cotidiano. Patrícia Splinder (2005), psicóloga e professora de dança que acompanhou um grupo de mulheres da terceira idade numa oficina que ministrava, compartilha suas inquietações quanto à referida discussão, às quais se aproximam da vivência experimentada pela profissional do Centro de Referência: 
O que estava explícito era que aquele espaço era para aprender e exercitar dança, e isso tem suas limitações, no sentido de que eu percebia e tentava proporcionar com aquele espaçotempo. Porém, será que elas teriam os mesmos desejos que eu? Aquele movimento não passava por uma sutil invasão em suas vidas e a respeito do que vieram fazer ali? Fico pensando até que ponto devia esclarecer essas questões com elas, ou ao invés, escutar, acolher e alimentar o que elas me traziam, me solicitavam e demandavam enquanto um espaço que vai além dos propósitos de uma aula de dança. (p. 269-270).

Em relação às oficinas de corpo e dança, o trabalho interdisciplinar pôde ser construído a partir do momento em que as pessoas envolvidas nessa oficina passaram a dialogar sobre as atividades que seriam realizadas nas aulas. Poucos meses após o início das atividades, foi construído um espaço de supervisão conjunta - composta pelas supervisoras acadêmicas e de campo, pela profissional que acompanhava a oficina e pelas estagiárias que as ministravam, que muito contribuiu para o andamento dos encontros. As supervisões aconteciam semanalmente e a cada quinze dias era reservado um espaço para leitura de textos da temática corporal e da dança. Além de dividir impressões com as professoras e acompanhar a construção das aulas, esse espaço foi significativo para a evolução do trabalho a partir do momento que passou-se a construir, conjuntamente, as atividades propostas para as oficinas.

Ao longo do trabalho foi possível que surgisse um espaço de troca e eram notáveis as-transformações na atuação da profissional e das estagiárias a partir da fusão dos saberes compartilhados. Modificações corporais e descobertas vivenciadas foram surgindo a partir da intervenção da dança no corpo de uma psicóloga. Havia um olhar mais sensível às falas e aos sinais comportamentais que a psicologia fazia emergir na dança. A partir desse diálogo, construções conjuntas das aulas foram sendo desenvolvidas, compartilhando saberes distintos de cada área, tendo como foco programas de aulas semanais que atendessem às necessidades, aos desejos, às expectativas, e também que atingissem amplamente o desenvolvimento de cada mulher. Assim, pode-se perceber que a dinâmica interdisciplinar contribui para o desenvolvimento mais completo das atividades.

A possibilidade de ter um espaço de troca entre áreas distintas, seja para discutir as impressões das oficinas, seja em relação aos atendimentos realizados, contribui para uma visão integral da mulher. As reflexões que surgiram permitiram um aprimoramento e uma qualificação dos profissionais envolvidos, bem como construía um diálogo entre as possíveis intervenções que possibilitava um desenvolvimento amplo das potencialidades das participantes.

A parceria entre a dança e a psicologia na atuação junto às mulheres foi bastante positiva. Era nítida a diferença entre o modo como as mulheres iniciaram as oficinas e o trabalho final. Os espaços de reflexão, troca de ideias e compartilhamento de experiências, possibilitados pelo trabalho em conjunto das estratégias dos saberes da Dança e da Psicologia, propiciaram que o grupo ganhasse corpo.

\section{Os corpos nas oficinas}

As oficinas de dança têm como eixo norteador o desenvolvimento da corporeidade feminina a partir de práticas e reflexões que envolvem a consciência, a sensibilização e o domínio do corpo. Objetiva-se a conscientização de um corpo integrado, onde o físico, o pensamento e o sentimento se complementam. Nesse processo, é fundamental a redescoberta do espaço que esse corpo potente pode ocupar por meio da ampliação de seus sentidos e da descoberta de suas potencialidades corporais.

Perceber corpo e mente como integrados permitiu novas leituras sobre a forma de entender o comportamento humano. Essa integração nos permite um outro olhar sobre esse corpo, onde produções de inúmeras ordens podem se realizar. Fernando Pocahy (2014), em um artigo que conversa sobre gênero, envelhecimento e sexualidade, utiliza o corpo como cenário e afirma:

Arrisco dizer, seguindo os rastros foucaultianos, que o corpo pode ser também uma heterotopia - um espaço outro, lugar outro, não somente onde habitam os discursos 'habilitantes' e 'desabilitantes' mas por onde temos a sorte de sairmos transformados - o corpo como experiência, o corpo como resistência, o corpo como obra de arte. (p. 177).

Refletindo sobre algumas falas marcantes de uma usuária (D.), nota-se o quanto este corpo, que se coloca no mundo, se exercita diariamente, que por vezes é irreverente no modo de vestir - se 
distanciando do aspecto socialmente esperado para uma senhora de aproximadamente oitenta anos de idade - também encontra no espaço das oficinas um meio de resgatar parte de suas histórias, lembranças e afetos. Marcia Moraes et al (2014), ao compartilhar sobre trabalho em grupos, discorre:

Nos encontros da Oficina colhemos memórias, sentimentos e histórias que estão marcadas no corpo de cada um. É a experiência expressa através dos músculos, dos gestos, da maneira de andar, de falar e da postura corporal. Quando somos afetados, modificamos nosso corpo de forma ímpar, pois nosso corpo armazena memórias e a cada interação, modificase a percepção do mundo e do próprio eu. Há um ciclo sem fim, onde o corpo sente, interage, recupera e armazena memórias. (p.57).

Nos encontros semanais com as mulheres foram desenvolvidos processos de (re)descoberta, aceitação, conscientização, potencialização e empoderamento do corpo por meio das atividades que trabalham a consciência corporal, o alongamento, o relaxamento, a respiração, a criação artística e coreografia. Para a presente reflexão, destaca-se a criação a partir de laboratórios (pesquisas) coreográficos como forma de descobrir novas possibilidades de se expressar a partir do movimento, de explorar os pensamentos, os questionamentos, a criação, a atitude, os impulsos e os desejos, proporcionando, assim, novas experiências que, desenvolvidas, estruturadas e ensaiadas, passam a ser trabalhos de composição coreográfica.

Durante todo o processo de desenvolvimento corpóreo da oficina sociocultural de corpo e dança, modificações corporais puderam ser observadas nas mulheres que frequentaram assiduamente as aulas. Mudanças instantâneas e/ou transformações a longo prazo, como por exemplo, relaxamento das tensões, alívio de dores musculares, concentração, organização postural, aumento da coordenação motora, do equilíbrio, da flexibilidade e do ritmo, bem estar, desinibição, entre outros:

Durante todo o trabalho de aquecimento, as mulheres responderam muito bem aos exercícios propostos, vejo cada vez mais a descoberta ao se moverem, uma melhora na consciência corporal" (Relato $1604 \mathrm{E} 1)$.

Podemos constatar esses avanços a partir de observações constantes perante as mulheres, e também pelos próprios relatos das usuárias. Algumas, ao chegarem à oficina de corpo e dança, mostravam-se tensas fisicamente e relatavam dores em pontos específicos do corpo, sem diagnóstico médico. Ao longo de suas participações, algumas usuárias compartilhavam melhoras no que tange às dores que sentiam anteriormente e se surpreendiam ao conhecer as possibilidades de execução de movimento de seus corpos e de relaxamentos tão profundos durante a realização de alguns exercícios.

São perceptíveis essas mudanças corporais nas mulheres que se propuseram a separar um tempo para olhar e cuidar do seu corpo, deixando aguçar e ampliar o conhecimento das possibilidades de movimento. Dessa forma, constrói-se uma nova postura perante seu corpo e o espaço em que se insere. Assim, pôde-se perceber que a oficina de corpo e dança possibilitou melhoria das relações corpóreas e da vida cotidiana das mulheres.

Por entender o corpo como um território possível de transformações e um local de resgate de sentidos da vida, a proposta das oficinas socioculturais de corpo e dança consiste em desenvolver estratégias de resgate da cidadania feminina a partir da descoberta e experimentação de si, tendo o corpo como um lugar a ser trabalhado, desenvolvido e potencializado. Além disso, a participação e disponibilidade de uma profissional professora/educadora em ser facilitadora desse processo foi de fundamental importância. Jussara Miller (2014), ao falar sobre o processo de educação-corpo-dança, destaca o papel do educador nesse cenário:

Assim, reconheço que as ações de um educador de dança não se limitam a ensinar danças, mas devem, principalmente, provocar experiências, sensibilidades e reflexões. A dança como experiência e como processo, aqui abordada, foca a prontidão de estar em pesquisa e não o estar em treinamento para algo que virá depois, desvinculado do que se frui. A proposta é trabalhar diariamente a escuta de si. (p. 109). 
O espaço da oficina de corpo e dança, por vezes foi escolhido pelas participantes, como um local onde elas acreditam que aprenderão algum ritmo ou passos de danças específicas. Deixar o corpo disponível para o toque, o encontro com o outro e consigo mesmo, não era tarefa das mais simples. Nas oficinas, o corpo apresentava uma linguagem própria que permitiu a construção de espaços de fala sobre vivências, emoções e sensações de uma forma bastante singular. O corpo tornou-se portavoz do que elas pretendiam (e conseguiam) expressar naquele dia ou naquela semana.

Olhar para o corpo agitado, cansado, esgotado era o desafio. Em cada encontro buscava-se a disponibilidade para o contato com o próprio corpo.

Iniciei a aula de hoje realizando uma chegada, onde as mulheres se deitavam ao solo para relaxar e buscar a tranquilidade, concentração e a quietação dos corpos agitados do cotidiano, voltando o olhar para si e sensibilizando o corpo a partir de estímulos dados pela minha fala e por uma música tranquila. Busquei concentrá-las de forma que esquecessem o mundo fora da sala e buscassem a paz na corporeidade. Realizei um "raio x do corpo" onde as mulheres podiam dar uma atenção maior para as partes do corpo primeiramente isoladas e depois do corpo como um todo, percebendo seu peso, temperatura, formato, partes que encostam ao chão ou não, batimentos, respiração, sentimentos, pensamento, entre outros. As mulheres reagiram muito bem a essa chegada, todas foram aos poucos se concentrando e relaxando para focar na aula.[...] M, comentou ao fim da atividade que essa parte da aula era muito boa, relatou que podia ser assim a aula toda. Percebi que C, estava um pouco agitada hoje. (Relato $3005 \mathrm{E} 1$ ).

Uma questão simples e profunda refere-se ao fato de que, construímos com as mulheres, ao longo do tempo, um espaço onde elas poderiam diariamente perceber, primeiramente, como estavam se sentindo como mulheres, em relação ao seu corpo e tudo que o circulava, tanto nas questões sociais como individuais. O espaço que construímos estimulava as mulheres a voltar seu olhar para si em todos os aspectos e se manifestar, muitas vezes, não com o objetivo de expor para os outros, mas expor para si mesmas como se sentiam. Pode-se supor que a não existência desse espaço impossibilitaria que as mulheres se despertassem para questões tão profundas acerca de si próprias e não teriam outro espaço para experienciar a si mesmas. Um corpo feminino que muitas vezes é culturalmente colocado como coisa que deve alcançar um modelo ideal e, nesse espaço, se apresenta como um corpo sensível, pensante, falante que queria se colocar como estava sendo naquele momento, mesmo que ainda trouxesse os julgamentos sobre si, o fato de reservar um momento para se perceber, já era uma maneira de se valorizar.

\section{As falas nas oficinas}

Dentro do CRMM-CR a experiência com o corpo na oficina de dança levantou muitas questões antes mesmo do seu início. Tanto as estagiárias, quanto a profissional e as supervisoras que participaram da construção da oficina, não podiam ter certezas quanto ao desdobramento da proposta, por se tratar de algo novo. Não sabiam ao certo como as mulheres iriam se comportar dentro desse novo espaço e dessa outra forma de se relacionar com o corpo que o programa da oficina propunha. Tendo em vista que o corpo se colocaria como o foco do processo, era esperado que, em geral, as manifestações por parte das mulheres fossem corporais, porém, não havíamos considerado o fato de que a fala não se exclui de um trabalho corporal. O som da voz, as palavras escolhidas, a maneira como o rosto se movimenta, não são algo a parte do corpo e, portanto, não deixam de fazer parte do que se chama dança. A fala é a maneira mais usual de nos expressarmos no cotidiano, mas, mesmo propondo outras maneiras de se expressar, as mulheres que participavam das oficinas, traziam a fala como um elemento de ligação entre os movimentos.

Durante as oficinas, as falas iniciais que nos chamavam a atenção era a dos primeiros dias de contato com as mulheres que trazia uma prévia sobre aqueles corpos e de sua relação com a dança. As falas nos davam algumas direções por onde deveríamos começar as nossas investidas e, desde o início, a relação conflituosa que a mulher adquire ao longo da vida com o corpo esteve presente. Esse conflito se dá, entre outros atravessamentos, pois vivemos numa cultura que valoriza determinados formatos corporais, por exemplo. 
Os meios de comunicação em massa enaltecem o corpo magro como sinônimo de beleza e saúde. Assim, muitas mulheres traziam o desejo de alcançar um corpo magro fazendo aulas de dança, uma expectativa que, com o tempo, foi sendo questionada, pois dentro de nossa proposta de trabalho, a valorização e o despertar daquele corpo que estava diante de nossos olhos, era o que nos interessava e não o alcance de um corpo tido por ideal:

C, na aula de hoje, falou bastante. Disse, insistentemente que se sente ridícula, que não se acha bonita e que como não tem dinheiro, não pode se cuidar. Investigávamos o que era se cuidar e estar bonita pra ela, mas C. prosseguia sua sensação de inferioridade. Repetia que seu maior sonho era ir no salão fazer o cabelo e as unhas. Disse-nos que só fez as unhas no salão uma única vez. Fala ainda que não sobra dinheiro para outras coisas. Só o essencial. $\mathrm{E}$, ao final, diz que tem poucas roupas e gostaria de se vestir melhor. (Relato $0606 \mathrm{P}$ ).

A temática corporal percorrendo certos padrões de beleza também atravessou o espaço das oficinas. As participantes, em sua grande maioria, se mostravam insatisfeitas com seus corpos, ansiando por ter um corpo magro que elas (e boa parte da sociedade) acreditam ser o mais belo. Com o intuito de desenvolver junto às participantes reflexões em relação ao modo como esse corpo apresenta diversas formas possíveis, de acordo com o momento histórico vigente, levamos um material para oxigenar nossa discussão. No entanto, fixadas em propagandas estéticas e ideais corporais, por vezes, havia certa resistência quanto a outro modo de perceber esse corpo.

A violência sempre foi um elemento que fazia parte das falas. Os corpos não denunciavam de maneira explícita os sofrimentos a partir das experiências de violência, mas as falas verbalizavam a violência vivida dentro da comunidade em relatos constantes que, muitas vezes, atravessavam as oficinas permitindo a construção de uma outra configuração daquele espaço, onde as falas e as opiniões eram pronunciadas e valorizadas tanto quanto o trabalho corporal. Era preciso apenas uma intervenção por parte das professoras para que fatos de anos anteriores fossem recordados, ora com certo grau de sofrimento, ora com prazer e alegria.

Um assunto que percorreu as nossas oficinas foi a situação da mulher negra, mesmo que com pouca intensidade. Assuntos como esse, no entanto, não surgiam de forma espontânea. Para explorar a fala nas oficinas, sempre que alguma data significativa, como o dia da mulher negra caribenha e latino-americana - comemorado no dia vinte e cinco de julho - ou dia da consciência negra- vinte de novembro - se aproximavam, nos organizávamos para conversar sobre os temas. Nesses encontros, questões como identidade, racismo, aceitação e valorização dos estereótipos da pessoa negra, apareciam. Porém, notávamos o quanto discutir tais questões se configurava com certa dificuldade para algumas mulheres, tanto em relação a se reconhecerem como sendo negras, quanto em problematizar a situação do negro no Brasil.

O segundo momento da aula de hoje [...] foi reservado para que discutíssemos o material sugerido por uma estagiária de Psicologia do CRMM-CR afim de pontuar o dia 25 de Julho. [...] Outra questão levantada foi a de que notou poucas pessoas negras num dos vídeos. Falou que uma delas até parecia com sua filha mais velha. E daí diz: "se for assim, então minha filha é negra também". [...] Pareceu-nos que as participantes tomaram um certo cuidado ao falar sobre o tema como se fosse um assunto que necessitava de certos cuidados para o discurso não parecer preconceituoso. (Relato 2207 P).

Se inicialmente os espaços de fala na oficina de corpo e dança apareciam com maior conteúdo de relatos durante o momento do café, parte final das aulas onde as mulheres e profissionais se reuniam e confraternizavam, no decorrer dos encontros, verbalizar sobre os acontecimentos do cotidiano, durante as atividades que eram desenvolvidas, possibilitou que as participantes construíssem com o grupo um espaço de troca, acolhimento e afinidade entre as participantes.

\section{Considerações finais}

Corpo como espaço de construção. Falas a partir do corpo. Corpos possibilitando momentos de fala. Falando com o corpo. Dança movimento. Essas e outras questões percorreram os espaços das 
oficinas de corpo e dança. Atentar para esse corpo que é plural, por sofrer influência de diversos meios, permite uma ampliação sobre as distintas formas de se trabalhar e desenvolver projetos na temática de gênero e potencialidades corporais. A experiência compartilhada a partir do referido artigo é um exemplo.

O trabalho em grupo se mostrou significativo, uma vez que possibilitou trocar e/ou compartilhar situações que elas pouco ou quase nunca falavam. À medida que os encontros avançavam, os assuntos se desenvolviam e as falas e lembranças de episódios de violência ou privações financeiras, bem como seus anseios e frustrações diante da vida, apareciam. A proposta era de criar um espaço onde houvesse acolhimento dessas demandas que elas traziam. No entanto, alguns temas nem sempre eram bem recebidos no grupo como, por exemplo, a questão do vestuário de algumas mulheres, o aborto e questões raciais.

A partir de uma construção coletiva das atividades, havia um esforço para que se problematizassem todas essas questões. As reuniões e supervisões eram momentos em que os entraves do grupo podiam ser expostos e surgiam propostas de desenvolver determinados temas a partir de algum novo dispositivo - vídeos, aulas expositivas, criações com tecido, papel, lápis de cor, etc. A junção de distintas áreas do conhecimento permitiu um olhar integral sobre as mulheres participantes, entendendo a indissociabilidade entre corpo e mente.

\section{Agradecimentos}

Agradecemos a participação das mulheres pela entrega corporal para a prática da oficina. Agradecemos às professoras Lilia Guimarães Pougy, Maria Ines Galvão Souza, Denise Sá, Hebe Signorini Gonçalves pelo trabalho de supervisão; à toda a equipe do Centro de Referência de Mulheres da Maré Carminha Rosa e ao Núcleo de Estudos de Políticas Públicas em Direitos Humanos (NEPP-DH), órgão suplementar do Centro de Filosofia e Ciências Humanas $(\mathrm{CFCH})$ da Universidade Federal do Rio de Janeiro.

\section{Referências bibliográficas}

ARDILA OSORIO, Gina Paola. Possibilidades e limites da dança para o empoderamento das mulheres: um olhar da saúde coletiva. Dissertação de Mestrado. São Paulo, 2015. 128 p. Disponível em: <http:/ / www.teses.usp.br/teses/disponiveis/5/5137/tde-26102015-153202/pt-br.php>. Acesso em: 27 mar. 2017.

COUTO, Leandra Lúcia Moraes; SCHIMITH, Polyana Barboza; DALBELLO-ARAUJO, Maristela. Psicologia em ação no SUS: a interdisciplinaridade posta à prova. Psicol. cienc. prof., Brasília , v. 33, n. 2, p. 500-511, 2013 . Disponível em: <http://www.scielo.br/ scielo.php?script=sci_arttext\&pid=S1414-98932013000200018\&lng=en\&nrm=iso $>$. Acesso em: 20 mar. 2017.

CRUZ, Roberto Moraes. Formação científica e profissional em psicologia. Psicologia: Ciência e Profissão, 36(1), 3-5. 2016. Disponível em: http://webcache.googleusercontent.com/ search?q=cache:4VeA3Ip3ey4J:www.scielo.br/pdf/pcp/v36n1/1982-3703-pcp-36-10003.pdf $+\& c d=1 \& h l=p t-B R \& c t=c l n k \& g l=b r$ Acesso em: 10 mar. 2017.

DACOME, Ocimar Aparecido. Resistência ao trabalho interdisciplinar: uma possível interpretação. Psicol. estud., Maringá , v. 5, n. 1, p. 85-103, mar. 2000 . Disponível em: <http://www.scielo.br/ scielo.php?script=sci_arttext\&pid=S1413-73722000000100006\&lng=pt\&nrm=iso $>$. Acesso em: 22 mar. 2017.

GONSALVES, Emmanuela Neves. Oficinas Socioculturais: possibilidades de ampliação do acolhimento às mulheres em situação de violência. Anais [do] 18. Encontro Nacional da Rede Feminista Norte e Nordeste (REDOR), Recife : EDUFRPE, 2015.

MILLER, Jussara. O corpo presente: uma experiência sobre corpo-educação. Revista ETD- Educação Temática Digital, 16 (01), 100-114. 2014. Disponível em: <http://www.fe.unicamp.br/revistas/ged/etd/ article/view/6172>. Acesso em: 23 fev. 2017. 
MORAES, Marcia; ALVES, Camila Araújo; OLIVEIRA, Josselem Conti de S.; MIGNON, Larissa Ribeiro; PAULA, Lia Paiva; MOUTINHO, Tayana Valente; CUNHA, Thainá Rosa Oliveira da; CAVALCANTI, Thiago José Bezerra. Corpo, memória e testemunho: cheiros que deixam marcas. (pág. 51- 71) In; O Tempo e a Escuta da vida. Quartet, Rio de Janeiro, 2014.

POCAHY. Fernando. O corpo como heterotopia(?): Problematizações na cama do gênero, da sexualidade e do envelhecimento. In: Anderson Ferrari; Cláudia Maria Ribeiro; Roney Polato de Castro; Vanderlei Barbosa. (Org.). Corpo, gênero e sexualidade.1ed.Lavras: Editora da UFLA, 2014, v. 01, p. 177- 183.

RAMOS-CERQUEIRA, Ana Teresa de Abreu. Interdisciplinaridade e psicologia na área da saúde. Temas psicol., Ribeirão Preto, v. 2, n. 3, dez. 1994 . Disponível em: <http://pepsic.bvsalud.org/ scielo.php?script=sci_arttext\&pid=S1413-389X1994000300005\&lng=pt\&nrm=iso $>$. Acesso em: 17 jan. 2017.

SOUZA, Higor Linhares de; GONSALVES, Emmanuela Neves; SILVA, Pamella Valadares Console. Oficinas Socioculturais: uma proposta dialógica para o enfrentamento à violência de gênero. Seminário Internacional Fazendo Gênero 10 (Anais Eletrônicos), Florianópolis, 2013. Disponível em: http:// www.f g 2013 . w w c 2017 . eventos.dy pe.com.br/resources / a n a is / $20 /$ 1373320078_ARQUIVO_artigocompletooficinassocioculturais-fazendogenero.pdf. Acesso em: 15 fev. 2017.

SOUZA, Higor Linhares de. Oficinas Socioculturais. Projeto PIBEX/UFRJ 2014.

SPLINDER, Patrícia. Dança: uma ferramenta potencializadora da subjetividade. Mnemosine. V. 01, n. 01, Pág. 262-276. Disponível em: <http://www.mnemosine.com.br/ojs/index.php/mnemosine/ article/viewFile/53/pdf_39>. Acesso em: 25 jan. 2017.

Recebido para publicação em 13/9/2017 e aprovado em 16/11/2017.

${ }^{6}$ Disponível em: <http://www.scielo.br/>. Consultado em: 12 mar. 2017.

${ }^{7}$ MOTTA, M. Teoria Fundamentos da Dança: uma abordagem epistemológica à luz da Teoria das Estranhezas. Dissertação de mestrado. Niterói/ IACS, 2006.

${ }^{8}$ O Parque Henrique Lage (http:/ / eavparquelage.rj.gov.br/;) é um parque público da cidade do Rio de Janeiro localizado na Zona Sul da cidade e a Quinta da Boa

Vista é um parque municipal localizado na Zona Norte. (http:/ / www.rio.rj.gov.br/web/riozoo/conheca-a-rio-zoo). 